\title{
Surgical Treatment Methods in Movement Disorders: Mechanisms of Action and Indications
}

\author{
Bekir Enes DEMIRYÜREK', Banu Özen Barut²
}

Clinif of Neurology, Sakarya Training and Research Hospital, Sakarya, Turkey

Clinif of Neurology, Kartal Lütfü Kurdar Training and Research Hospital, İstanbul, Turkey

\section{ABSTRACT}

Movement disorders display complex pathophysiologies. The first step in their management is medical treatment. However, if medical treatment is an inadequate or cannot be used because of side effects, surgical treatment should be considered. Surgery is used to treat essential tremors, Parkinson disease, and dystonia. There are two types of surgery currently available: lesioning and neurostimulation. A method called DBS is more preferable than lesioning because its outcomes are reversible and it has a low ratio of morbidity. However, conservative surgical approaches continue to be used for treating some movement disorders. This review discusses lesioning and neurostimulation in the treatment of movement disorders.

Keywords: Movement disorders, lesioning, DBS, tremor, parkinson disease, dystonia

\section{Introduction and History}

Movement disorders are characterized by changes in normal motility, tonus, and posture in a single or combined manner. They do not include motor paralysis, severe sensory loss, painful syndromes, or skeletal deformities. However, they may develop because of disorders of cerebral hemisphere, cerebellum, and metabolism and brain stem lesions. Movement disorders most commonly develop depending on the extrapyramidal system [basal ganglia (BG)] that is affected in the brain (1).

This disease group, which is also called as BG diseases, is caused by the abnormalities in the BG and related structures. The BG structures are shown in Table 1 .

Although the physiopathologies of the conditions that lead to movement disorders maintain its complexity, several studies have been conducted to elucidate the anatomy and physiology of the BG. The BG, the main task of which is controlling, fine-tuning, and modulating response, has to receive information (afferent stimuli) from the areas to be controlled and fine-tuned and has to give information (efferent stimuli) to those areas for performing these functions. Most of the afferent inputs to the BG come from the frontal cortex. The main formation through which these afferent signals enter the BG is the striatum. The output gate of the information processed in the BG is also limited, and output signals are transmitted by the globus pallidus internus $(\mathrm{GPi})$ and substantia nigra reticularis $(\mathrm{SNr})$. Most of the efferent signals of the BG travel to the thalamus. In recent years, the internal organization of the skeletomotor circuit of the BG has been better understood. Accordingly, there are two subcircuits or pathways that function as opposite or complementary to each other - direct and indirect pathways. The signals entering the putamen from the cortex through the direct pathway bypass the BG and travel toward the exit gate, i.e., the GPi and $\mathrm{SNr}$ and return to the cortex via the thalamus. In the indirect pathway, the signals entering the putamen from the cortex move toward the exit gate, i.e., the GPi/SNr after passing through the intermediate stations of the globus pallidus externalis and subthalamic nucleus $(\mathrm{STN})$, and they return to the cortex via the thalamus $(1,2)$.

Cite this article as: Demiryürek BE, Barut BÖ. Surgical Treatment Methods in Movement Disorders: Mechanisms of Action and Indications. Bezmialem Science 2017; 5: 126-34.

Address for Correspondence: Sakarya Eğitim Araştırma Hastanesi, Nöroloji Kliniği, Sakarya, Türkiye 
The first step in the approach to the treatment of movement disorders resulting from abnormalities in these pathways involves medical treatment. However, surgical treatment is needed for patients in whom this treatment is insufficient or in whom it cannot be applied because of the side effects. Two types of surgical options are available:conservative surgery (irreversible) and deep brain stimulation (DBS; reversible) (3).

The beginning of surgical treatments for movement disorders dates back to the early 1900s (4). These initial surgical procedures were performed as tremor therapy; postoperative complications, particularly those in which motor deficits occurred, were numerous. Spiegel et al (5) started using the stereotactic head frame system in the late 1940s, and eventually it became possible to focus on very small subcortical structures. Pallidotomy in Parkinson's disease (PD) was first attempted in 1952 by Narabayashi and Spiegel and Wycis ( 5 , 6). In 1953, Cooper (7) observed that tremor in a patient was dramatically improved because of accidentally connecting the anterior choroidal artery during pedunculotomy. In 1955, Hassler reported that thalamotomy was more useful in the treatment of tremor (8). Svennilson et al (9) reported in 1960 that the lesioning procedures performed in the posterior area in pallidotomy were more effective than those performed in the anterior area. In 1963, some authors reported that subthalamotomy successfully treats tremors at a rate which is similar to that of thalamotomy (10). With the introduction of levodopa in PD in 1967, surgical procedures became less frequent (11). In drug-resistant tremors, the surgical treatment of movement disorders regained prominence with the reapplication of thalamotomy in the 1980s (12). Laitinen et al (13) reported in 1992 that posteroventral pallidotomy was useful in PD motor symptoms. However, for the last 20-30 years, surgeries have increased due to the limitations and motor side effects of longterm levodopa treatment. However, in recent years, because of surgical complications and treatment failures, non-destructive and non-ablative structures which are easy to adapt and reversible and subcortical, have replaced DBS lesioning surgery the functions of which have the potential for use in research. The opinion that high frequency stimulation founded by Benabid et al in 1987 often mimicked the effects of the lesioning surgery and was effective was reinforced by several studies. Although initially used for the treatment of movement disorders, it has recently been initiated in neuropsychiatry (14-16). In this review, we discuss the role of surgical treatment approaches in movement disorders.

\section{Surgical Approaches}

Conservative surgical methods are available for the treatment of movement disorders or for complications developing due to medical treatment. Treatment is possible by surgical intervention in the thalamus, STN, and GPi, which are among the deep brain structures. Conservative surgery continues to be performed particularly in the treatment of tremor and dystonia, despite being replaced by DBS in recent years because it is irreversible and has side effects (15-18).
Thalamotomy: It is performed in the cases of PD-induced tremor in which medical treatment-resistant tremor occurs as a main symptom as well as in the cases of essential tremor, Holmes tremor, multiple sclerosis-related tremor, and ischemic and post-traumatic tremor. In contrast, it may be rarely performed in generalized dystonia and PD-associated dystonia. Ventralis intermedius (VIM) nucleus is the target nucleus for tremor in the thalamus $(17,18)$.

A stereotactic frame is placed on the head, and the target coordinates are calculated using magnetic resonance imaging. In recent years, microelectrode recordings have reduced the complication rates of surgeries (19). Patients with PD should be "off" during the procedure, and the medical treatment that is used for PD should be discontinued one day before. Under local anesthesia, the selected electrode is placed in the target coordinates without the loss of consciousness in the patient. The electrode is connected to a radiofrequency (RF) device and the desired temperature and duration are adjusted. During this procedure, necrosis occurs at the center and edema occurs around the target area. When the electrode reaches the target, a temperature of $42-44^{\circ} \mathrm{C}$ is applied for $1 \mathrm{~min}$, and temporary loss of function is created in the tissue. Whether the tremor has disappeared in the presence of tremor at this time as well as the findings, such as hemiparesis, hemihypoesthesia, and eye movement disorders should be evaluated. If tremor disappears without these side effects, a permanent lesion is created by performing the procedure at $80^{\circ} \mathrm{C}$ for $60 \mathrm{~s}$ in this area.

Postoperative computed tomography should be used to check the lesion area and whether it is hemorrhagic. The probability of bleeding after the procedure is less than $1 \%$. Infection can occur rarely $(3,15)$. Complication is much rarer in unilateral thalamotomy and is usually not permanent. While the mortality rate in a case series was $2.7 \%$ in previous years, this rate decreased to $0.3 \%$ depending on the recent developments in surgical techniquesyears. However, since bilateral thalamotomy operations are reported to mostly cause aphasia and complications, including ataxia, motor deficit, cognitive deterioration, dysphagia, homonym hemianopsia, and facial paresis, it is no longer performed (20).

Thalamotomy was frequently performed in Parkinson's surgery. Nowadays, it is performed infrequently compared to pallidotomy and STN neurostimulation. Thalamotomy is performed mainly in tremor-dominant PD. It has been observed in selected cases that the disappearance of tremor causes recovery in daily life activities (21). Tremor may recur several months after the surgery at a rate of $4 \%-20 \%$. Thalamotomy, however, provides cessation in tremor at a rate of $80 \%(18,21)$. It is also known that thalamotomy provides a decrease in the UPDRS motor subscore probably because the lesion in the anterior part of the zona inserta or ventrolateral nucleus also partially decreases the rigidity in thalamotomy. However, nowadays, the role of thalamotomy is limited in the treatment of $\mathrm{PD}$, and it is preferred only in the tremordominant patient group $(21,22)$. 

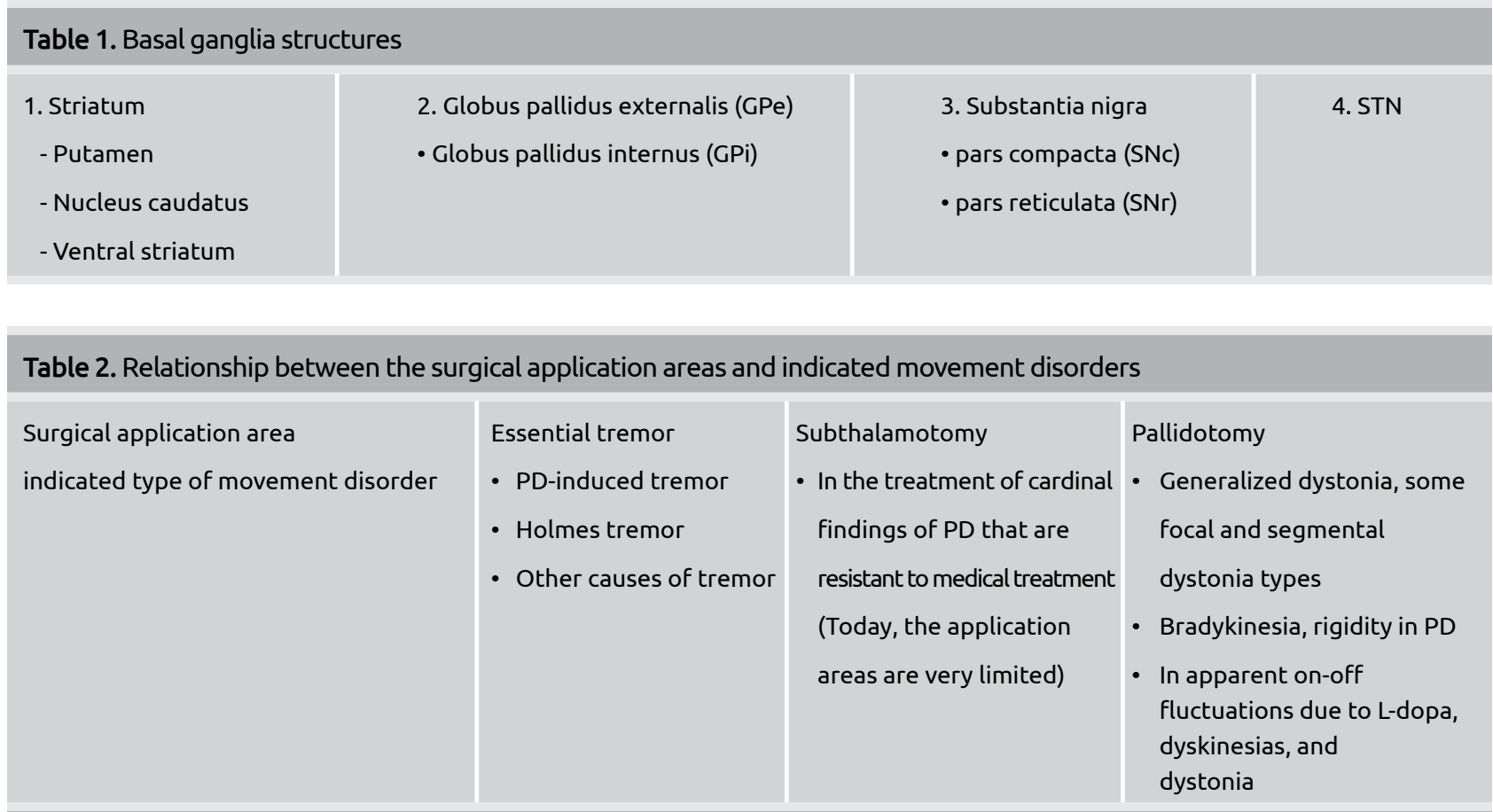

PD: Parkinson's disease BG: Basal Ganglia

Subthalamotomy: It is a lesioning procedure performed in the STN for the treatment of cardinal symptoms, such as bradykinesia and rigidity, when there is insufficient response to medical therapy in PD (17). The procedures in subthalamotomy are performed similar to those in thalamotomy. However, the STN coordinates are calculated as the target. The lesioning is performed at $80^{\circ} \mathrm{C}$ for 1 minute. After this procedure, stroke and hemiballismus can be seen. Subthalamotomy is now replaced by STN neurostimulation (3).

Pallidotomy: It is effective in generalized dystonia, bradykinesia in PD, rigidity, significant motor fluctuations, and levodopa-induced dyskinesias (18). The GPi is selected as the target. The above operations are also performed in pallidotomy. Because GPi is close to the optic tract, $2.5 \%$ of the patients experience visual field loss. Motor deficits can be observed because the lesion is close to the capsula interna. Speech may also be impaired in $8 \%$ of the patients. This temporary condition can be permanent in bilateral pallidotomy. At the same time, the bilateral pallidotomy has a higher risk of cognitive deterioration $(3,9,23)$. In their study, Strutt et al reported that pallidotomy was effective on motor symptoms, but in their long-term follow-up, they detected mild impairment in verbal and motor processing rates, particularly in mental condition and verbal memory (24). Although the mechanism of action of pallidotomy is not completely known, the most important cause in etiopathogenesis may be the direct destruction of internal GPi segments, the interruption of the pallidofugal pathways, or the decrease in the stimuli to the medial pallidum (particularly from the STN) (25). To date, pallidotomy is preferred particularly in patients developing on-dyskinesia depending on levodopa rather than on cardinal findings of PD. The decrease in dyskinesia increases quality of life and facilitates the increase of levodopa dose. However, the efficacy is limited in those with a long off period $(21,26)$.

Partial well-being is observed for about 2-7 years in pallidotomy cases; however, bradykinesia eventually becomes apparent due to disease progression and STN-DBS is indicated in many cases. For this reason, STN neurostimulation can often be preferred over pallidotomy in clinical practice. However, pallidotomy is performed in selected cases because it delays the progression of the disease, is cheaper, and does not interfere with STN-DBS operation to be performed later (21).

The application areas of lesioning surgery and the types of movement disorders it is effective on are summarized in Table 2 .

\section{Deep Brain Stimulation (DBS)}

\section{General Features}

Deep brain stimulation (DBS) also called as the neurostimulation surgery, which has been considered to be the fastest growing field of brain surgery in recent years, is widely used in many neuropsychiatric diseases (21-24).

DBS first originated when Spiegel and Wycis developed and described a stereotactic apparatus that could be used in ablative procedures in humans in 1947 and was used by Benabit and Pollac in 1987 as a treatment for tremor after many years of development. In 1991, it was introduced in literature as an alternative to the classical surgical treatment (27). 
Tablo 3. Relationship between the DBS application areas and the indications, risks, advantages, and disadvantages in movement disorders

\section{DBS Application Area Thalamic (VIM)}

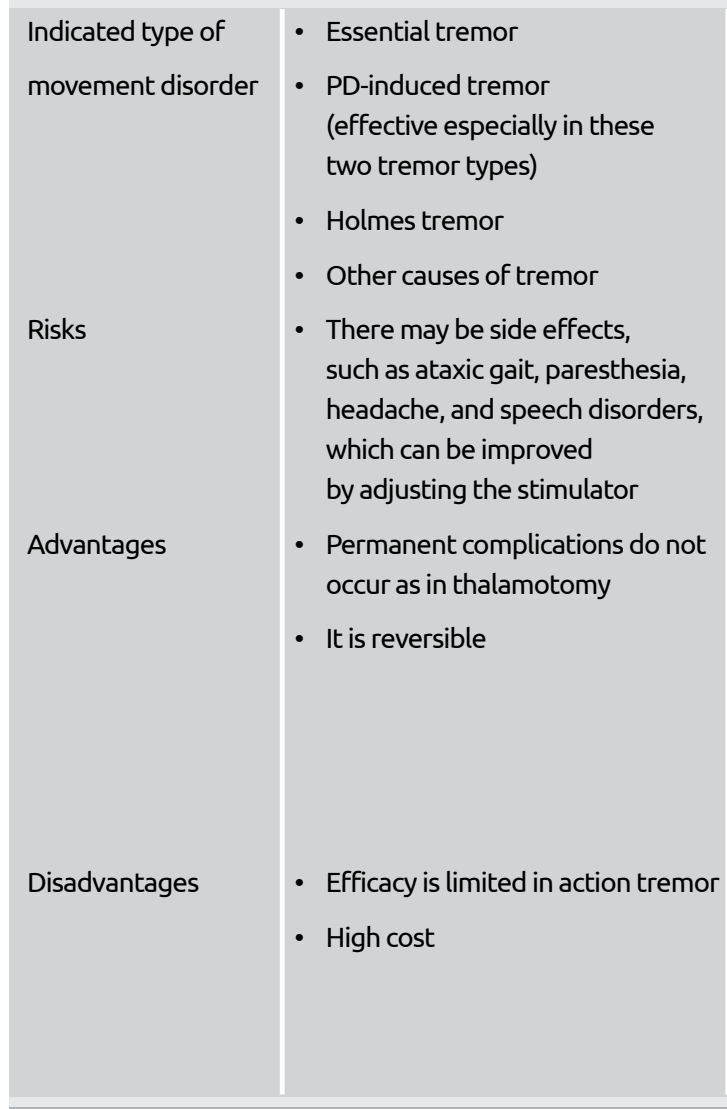

STN

- First choice in PD that is resistant to medical treatment (rigidity, bradykinesia)

- Similar to VIM stimulation, there may be side effects that can be improved by adjusting the stimulator

- It may increase depressive mood

- Complications of lesioning surgery are not seen

- In recent years, it has been started for the treatment of tremor that is resistant to VIM stimulation

It is reversible

High cost

- Ineffective in those with cognitive deterioration and even worsen cognition

\section{Pallidal (GPi)}

- Generalized dystonia, some focal and segmental dystonia types

- Bradykinesia, rigidity in PD

- In apparent on-off fluctuations due to levodopa, dyskinesias, and dystonia

- Similar to VIM stimulation, there may be side effects that can be improved by adjusting the stimulator

- Efficacy is not limited (7-8 years) as in pallidotomy

- Complications (particularly persistent cognitive deterioration) due to lesioning surgery (pallidotomy) do not occur

- It is reversible

- The efficacy does not start immediately as DBS that is applied in other regions; it becomes completely efficient after 8-12 weeks on average

- High cost

DBS: Deep Brain Stimulation; STN: Subthalamic Nucleus; PD: Parkinson's disease; VIM: Ventral Intermedius Nucleus; GPi: Globus pallidus internus

Today, DBS has been proven effective and is mostly used in movement disorders, PD, essential tremor, and dystonia (28). In recent years, it has also been used in the treatment of psychiatric disorders, such as major depression and obsessivecompulsive disorder, in some epilepsy patients, Tourette's syndrome, and in some Huntington's cases $(28,29)$.

Thalamic DBS for essential tremor and PD tremor was approved by the FDA in 1997; STN and GPi DBS were approved for PD treatment in 2003, for primary generalized and segmental dystonia in 2003, and for obsessive-compulsive disorder in 2009 (29-32).

Although the most frequently observed side effects of DBS are paresthesia, headache, dysarthria, gait disturbances, and ataxia, these side effects are often mild and can be corrected by adjusting the stimulation parameters (33). However, intracerebral lesions and infection are rarely observed (33). Infection rates vary between $1.7 \%$ and $4.5 \%$, although they change in different clinics. Studies have shown that intracerebral hemorrhage rates are less than $1.5 \%$ (34-36).

Although having a low rate of morbidity and being reversible and effective are the biggest advantages of DBS, its high cost seems to be the most important hurdle for it to become widespread. In a recent study, the DBS treatment was reported to cost $\$ 20,000$ in the US (37). However, there are opinions suggesting that the cost should be disregarded becaue of the fact that it increases the patient quality of life and decreases the future costs of treatment $(38,39)$.

\section{Application Method}

Similar to the surgical ablation method, the selected electrode is placed in the target coordinates under local anesthesia without loss of consciousness in the patient. After the localization of the coordinates during this placement is confirmed by macrostimulation or microstimulation and/or microelectrode recordings, a neurostimulator is placed on the chest or under clavicula, and the conduction between the electrode and the stimulator is provided by the cables. The stimulation is initiated on a regular basis during follow-ups, and neurostimulation is constantly performed at a fixed frequency after the efficacy and adverse effects association for the current symptom is established. The patient can switch on and off the stimulator with a button. The average life span of the battery of the first stimulators was 3-5 years, but the average life span of newly produced batteries is $9-10$ 
years. When the battery is depleted, it is replaced under local anesthesia $(28,29)$.

\section{Mechanism of action:}

The mechanism of action of DBS, which has been proven to be effective in PD, has not been completely explained. Theories proposed in this regard have suggested more than one mechanism of action underlying the therapeutic effect. Although some general principles are mentioned in relation to the effects that occur during DBS, the location of the stimulation and the factors associated with the disease also affect the consequences (40). The theories suggested for the mechanism of action of DBS are as follows:

a) Benabid et al. (41) suggested that electrical stimulation reduced basal firing in neurons and inhibited the spontaneous neuronal activity and the output activity in BG structures. According to this mechanism of action, which is called as depolarization blockade, the neuron cell bodies have the maximum firing rate, and stimulating these neurons with a stimulation that is higher than the maximum firing rate causes a continuous depolarization state and creates an ablation effect. The applications performed in the following areas are the examples for the mechanism of action that support the above theory and for the DBS applications that have been explained (42).

a. VIM: The stimulation of this pathway, projecting from the thalamus to the motor cortex, causes reduction in tremor.

b. STN: The stimulation of neurons projecting from STN to GPi/SNi pars reticulata causes the disappearance of PD signs, including tremor, rigidity, and bradykinesia.

c. GPi: The stimulation of neurons projecting to the motor thalamus reduces tremor, rigidity, and bradykinesia in PD. The stimulation of this region results in a delayed reduction in dystonia.

b) Most studies show an excitatory activity spreading from the stimulated neuronal target tissue. This paradoxical situation is explained by the fact that axons have a lower stimulation threshold than the cell body (40). The examples given to the effects of DBS according to this theory are as follows (42):

a. Central caudal nucleus of the thalamus: The stimulation of this region causes persistent paresthesia.

b. Posterior limb of the internal capsule: Tetanic muscle contractions and spastic dysarthria.

c. Optic tract: Visual light flashes.

c) Beyond these theories, there are also approaches suggesting that electrical stimulation disrupts pathological oscillatory patterns and forms an "informative lesion" by pre- venting the transmission of the pathological BG activity. As a consequence of all of these, it is thought that DBS causes a rapid regulatory effect and corresponding activation of compensatory mechanisms, as well as subsequent changes related to synaptic plasticity and anatomical reorganization (43).

\section{Rank in Movement Disorders}

Tremor: Recently, thalamic (VIM nucleus) DBS has begun to replace thalamotomy in the treatment of tremor (28-30). The efficacy of thalamic DBS in essential tremor and PD tremor has been proven. The efficacy of DBS treatment is limited in the treatment of action tremor developing due to various etiologic factors (28). It has been reported in many studies that bath unilateral and bilateral VIM stimulation provide a $40 \%-80 \%$ reduction in tremor severity and provide an indirect increase in quality of life (44-47).

While no improvement is observed in $10 \%$ of patients with upper limb tremor despite adequate stimulation, an increase is seen again in tremor a year of the improvement in $15 \%$ $20 \%$ of the cases. It is unknown whether this is because of the progression of the disease or because of the development of tolerance to neurostimulation (48-50).

Although the stimulation is known to have side effects, such as ataxic gait, paresthesia, headache, and speech disorders, these side effects are usually mild and can be corrected by adjusting the stimulator (28).

In recent years, STN stimulation has gained importance as an alternative to VIM in the treatment of tremor. STN stimulation is important because it shows an efficacy equivalent to VIM, it is effective on intention tremor, and its side effects and tolerance are considered lower than VIM neurostimulation $(51,52)$ in tremor therapy.

However, studies on STN stimulation in tremor therapy are limited, and it is attempted in cases resistant to VIM stimulation in many clinics (53).

Parkinson's Disease: After the STN neurostimulation was first performed in 1980, GPi and VIM neurostimulation are performed along with STN neurostimulation for the symptoms of PD. In PD patients receiving oral levodopa, dyskinetic motor fluctuations, deterioration of PD symptoms despite the increase in medical treatment doses, and tolerance to levodopa develops within $5-15$ years on an average. Despite optimal doses of levodopa, STN, and GPi neurostimulations are performed in patients with increased UPDRS motor scores and with levodopa complications. VIM neurostimulation is performed for the treatment in tremor-dominant patients $(54,55)$. Fasano et. al. $(56,57)$ and Castriot et al reported significant improvement in UPDRS scores and in motor complications due to levodopa in PD patients whom they observed for 8-10 years after STN stimulation. 
The effectiveness of DBS was indicated as "evident A" in literature with the support of other studies conducted in the following years (58).

STN stimulation is mostly performed in the major symptoms of PD. In a large study of 299 patients, Weaver et al showed that there was no significant difference between STN and GPi neurostimulation in terms of efficacy in the treatment of rigidity and bradykinesia in PD (59). However, in these and other studies, the need for levodopa after STN neurostimulation was found significantly less than that after GPi stimulation. Furthermore, the battery life was found longer and the stimulation current power was found lower in STN stimulation. In contrast, cognitive deterioration and depression were more frequent in STN stimulation $(60,61)$.

GPi is more effective in the treatment of levodopa-dependent dyskinesia and motor fluctuations $(62,63)$. VIM stimulation has not been found to be beneficial in the treatment of PD findings except for tremor and levodopa complications, and it is currently performed only in tremor-dominant PD cases $(64,65)$.

In recent years, there have been reports suggesting that neurostimulation in the pedunculopontine area is effective in the treatment of axial rigidity and freezing. However, more studies need to be conducted in this regard $(66,67)$.

The decision for DBS should definitely be made by a commission that includes neurosurgeons, neurologists specialized in movement disorders, anesthetists, and radiologists. The most important criterion for the selection of patients who are appropriate for DBS is good response to levodopa. The effectiveness of DBS is very limited and even doubtful in diseases progressing with the symptoms of Parkinsonism, except for idiopathic PD (68).

Except for the good response to levodopa, young age $(<70$ years); short duration of the disease; and the lack of apparent axial motor symptoms, dementia, psychiatric disease, and other comorbid diseases are the factors that increase the success of DBS (69-72).

While dementia is an exclusion criterion for DBS, mild cognitive impairment (MCI) is not a certain exclusion criterion. In contrast, after DBS, clinical pictures, such as increased cognitive deterioration, and particularly, the stabilization of verbal response are observed in cases with MCI. There are opinions suggesting that this deterioration develops depending on the surgical procedure $(73,74)$.

Psychiatric diseases are also not a definite exclusion criterion. However, there are studies that report that depressive mood is increased particularly after STN stimulation probably due to the decrease in dopamine uptake after stimulation $(75,76)$. However, impulse control disorder developing depending on the dopamine agonists regresses due to decreased dopamine uptake after STN stimulation $(77,78)$.
Therefore, in many clinics where DBS is performed, the stimulation procedure is not applied in patients aged $>70$ years and have cognitive deterioration and psychiatric disease.

Although there are many opinions regarding the timing of DBS, the traditional approach is that it should be planned in patients with motor fluctuations and dyskinesias and in whom UPDRS motor scores do not improve despite medical treatment. However, in recent years, there are opinions that argue on the application of early DBS. Furthermore, it has been reported that better responses may be obtained in patients who undergo early DBS because of their better response to levodopa. Meanwhile, they stated that patient quality of life would improve and that the possibility of motor and nonmotor complications would decrease $(78,79)$.

In the EARLYSTIM study, the UPDRS motor scores and quality of life were reported to have improved significantly after DBS in 251 early-stage PD cases (79).

In another study, however, it was noted that this study was not a homogeneous study involving PD cases. The reason for this is that the patients included in the EARLYSTIM study were young, had no dementia, psychiatric and comorbid diseases, and had high levodopa responses (53). Anti-Parkinsonian drugs should be discontinued prior to the operation to completely assess the efficacy of intraoperative stimulation in $\operatorname{PD}(28,53)$.

In the treatment of PD, Gamma Knife radiosurgery, which is another surgical method, is applied in patients for whom RF surgery and DBS cannot be performed due to various chronic morbid diseases and oral anticoagulant use (80).

Gamma knife is applied to the VIM nucleus in a way similar to VIM neurostimulation in this method, which is preferred because it is noninvasive and has a much lower complication rate than DBS $(81,82)$.

There are publications showing that it is as effective as DBS in the treatment of Parkinson's tremor and essential tremor. However, the field of use of STN and GPi that are performed for the treatment of PD are limited because their efficacy is lower than the DBS procedure, and they are irreversible (80, 81).

Dystonia: Although the pallidotomy method that has been long used in the treatment of dystonia is still used today, DBS is used in many subtypes of dystonia (28). In the treatment of dystonia, bilateral GPi neurostimulation is performed in PDinduced dystonia and in generalized dystonia (32).

When assessed with the Burk-Fahn-Marsden Dystonia Rating Scale (BFMDRS), a scoring scale for dystonia, GPi neurostimulation provided an improvement between $60 \%$ and $85 \%$ in patients with generalized dystonia (82). While this rate of improvement was between $50 \%$ and $70 \%(83,84)$ in patients with secondary (tardive) dystonia, a lower rate of $40 \%-50 \%$ was observed in patients with cervical dystonia (85). 
Unlike PD and tremor, recovery in generalized dystonia patients who undergo DBS occurs gradually within weeks. Full activity usually resumes after $8-12$ weeks $(28,33)$.

In recent years, there have been reports that GPi neurostimulation causes bradykinesia in patients with generalized dystonia; therefore, DBS has been introduced for the other basal ganglia structures in the treatment of dystonia. Nevertheless, more studies are needed in this regard $(86,87)$.

The relationship between DBS application areas and the indications, risks, advantages, and disadvantages is summarized in Table 3.

\section{Conclusion}

While the return to surgery in movement disorders has increased in recent years due to inadequate response to medical treatment and side effects, DBS has led to revolutionary developments in movement disorders as well as in other neuropsychiatric pictures in the last 15 years. Surgical treatment and DBS are performed in generalized dystonia and partial cervical dystonia in addition to essential tremor, Holmes tremor, and other tremor types. However, it is performed depending on inadequacy and complications of medical treatment in PD, which causes many pictures of movement disorders. Today, the types of surgical treatments are unilateral thalamotomy, pallidotomy, and neurostimulation (DBS). The neurostimulation method has been significantly updated in the last 10-15 years. In particular, bilateral STN-DBS provided a great opportunity for patients with predominant bradykinesia. However, thalamic DBS and thalamotomy are performed for essential tremor, PD-induced tremor, and other tremor reasons, and lesion based applications, such as GPi DBS and pallidotomy, are used for levodopa-induced on-dyskinesia and generalized dystonia. Despite the fact that DBS has been in the forefront in recent years, thalamotomy and pallidotomy are still used in selected patients.

Peer-review: Externally peer-reviewed.

Author Contributions: Concept - B.E.D., B.Ö.B.; Design B.E.D.; Supervision - B.Ö.B.; Analysis and/or Interpretation - B.Ö.B., Literature Review - B.E.D.; Writing - B.E.B.; Critical Review - B.Ö.B.

Conflict of Interest: No conflict of interest was declared by the authors.

Financial Disclosure: The authors declared that this study has received no financial support.

\section{References}

1. Fahn S, Jankovic J. Principles and Practice of Movement Disorders. Philadelphia: Churchill Livingstone/Elsevier, 2008.

2. Jankovic J, Tolosa E. Parkinson's Disease and Movement Disorders. 5th edition. Philadelphia: Lippincott Williams\&Wilkins, 2007.
3. Selçuk Göçmen, Murat Kocaoğlu, Göksemin Acar, Feridun Acar. Lesion Surgeries in the Movement Disorders. Türk Nöroşir Derg 2014, Cilt: 24, Sayı: 2, 200-203

4. Horsley V.Thefunctions of theso-called motor areas of thebrain. BMJ 124:5-28, 1909

5. Spiegel E, Wycis H, Marks M, et al: Stereo taxic apparatus for operations on the human brain. Science 1947; 106: 349-350. [CrossRef]

6. Limousin P, Speelman JD, Gielen F, Janssens M: Multi centre European study of thalamic stimulation in parkinsonian and essential tremor. J Neurol Neurosurg Psychiatry 1999; 66: 289296. [CrossRef]

7. Cooper I. Surgical alleviation of parkinsonism: Effects of occlusion of the anterior choroidal artery. J Am Geriatr Soc 1954; 11: 691-718. [CrossRef]

8. Hassler R. The influence of stimulations and coagulations in the human thalamus on the tremor at rest and its physiopathologic mechanism. Greenfield Godwin J, Russell D, (ed), Proceedings of the Second International Congress of Neuropathology, London. Amsterdam: Excerpta Medica, 1955

9. Svennilson E, Torvik A, Lowe R, et al. Treatment of parkinsonism by stereo tactic thermo lesions in the pallidal region. A clinical evaluation of 81 cases. Acta Psychiatr Scand 1960; 35: 358-77. [CrossRef]

10. Andy O, Jurko M, Sias F. Subthalamotomy in treatment of parkinsonian tremor. J Neurosurg 1963; 20: 860-70. [CrossRef]

11. Cotzias G, Woert MV, Schiff er L. Aromatic amino acids and modification of parkinsonism. N Engl J Med 1967; 276: 37479. [CrossRef]

12. Tasker R, Siqueira J, Hawrylyshyn P, Organ LW. What happened to VIM thalamotomy forParkinson's disease? Appl Neurophysiol 1983; 46: 68-83.

13. Laitinen L, Bergenheim A, Hariz M. Ventro postero lateral pallidotomy can abolis hall parkinsonian symptoms. Stereotact Funct Neurosurg 1992; 58: 14-21. [CrossRef]

14. Kuhn J, Gründler TOJ, Lenartz D, Sturm V, KlosterkötterJ, HuffW. Deep brain stimulation for psychiatric disorders. Dtsch ArzteblInt 2010; 107: 105-13.

15. Schläpfer TE, Bewernick BH. Deep brain stimulation for psychiatric disorders-state of the art. Adv Tech Stand Neurosurg 2009; 34: 37-57. [CrossRef]

16. Stelten BM, Noblesse LH, Ackermans L, Temel Y, VisserVandewalle $\mathrm{V}$. The neuro surgical treatment of addictions. Neurosurg Focus 2008; 25; E5. [CrossRef]

17. Akgün Y, Peker S. Tremor tedavisinde cerrahi girişimler. ACU Sağlık Bil Derg 2010; 1: 123-127.

18. Barlas O. Hareket bozuklukları cerrahisi. Korfalı E, Zileli M (ed), TND Temel Nöroşirürji 2010; 2: 2073-74

19. Hariz MI. Complications of deep brain stimulation surgery. Movement Disorders 17 supp. 2002; 3: 162-66. [CrossRef]

20. Yavuz C, Hanağası HA, Şahin HA, Emre M, Barlas O. Bilateral Parkinson tremorunun bilateral küçük talamotomi ile tedavisi. Türk Nöroşirürji Dergisi 2002; 12: 242-46.

21. Ali Savaş, Cenk Akbostancı. Parkinson Hastalığında Derin Beyin Stimülasyonu, Türk NöroşirDerg 2014; 24: 168-72.

22. Tasker RR. Thalamotomy. Neurosurg Clin N Am 1990; 1: 841864.

23. Hariz MI. Pallidotomy for Parkinson's disease. Textbook of Stereotactic and Functional Neurosurgery 2009; 1540-41

24. Strutt AM, Lai EC, Jankovic J, Atassi F, Soety EM, Levin HS, et al. Five-yearfollow-up of unilateral posteroventral pallidotomy in Parkinson's disease. Surg Neurol 2009; 71: 551-58. [CrossRef] 
25. Çırak B. Parkinson hastalı̆̆ının cerrahi tedavisi. Oruçkaptan H, (ed), Greenberg Nöroşirürji El Kitabı, altıncı baskı. Ankara, Güneş 2013; 366.

26. Okun MS, Vitek JL. Lesion therapy for Parkinson's disease and other movement disorders: Update and contra versies. Movement Disorders 2004; 19: 375-89. [CrossRef]

27. Benabid AL, Pollak P, Gervason C, Hoffmann D, Gao DM, Hommel M, et al. Long-term suppression of tremor by chronic stimulation of the ventral intermediate thalamic nucleus. Lancet 1991; 337: 403-06. [CrossRef]

28. Başak Bolluk Kılıç, Selçuk Peker, Deep Brain Stimulation (DBS). History, Mechanisms of Action and Indications, Türk NöroşirDerg 2014; 24: 250-56.

29. Schuurman PR, Bosch DA, Bossuyt PM, Bonsel GJ, vanSomeren EJ, de Bie RM. A comparison of continuous thalamic stimulation and thalamotomy for suppression of severe tremor. N Engl J Med 2000; 342: 461-68. [CrossRef]

30. Deep-Brain Stimulation for Parkinson's Disease Study Group: Deep-brain stimulation of the subthalamic nucleus or the pars interna of the globus pallidus in Parkinson's disease. N Engl J Med 2001; 345: 956-63. [CrossRef]

31. Krack P, Pollak P, Limousin P, Hoffman D, Xie J, Benazzouz A, Benabid L. Subthalamic nucleus or internal pallidal stimulation in young onset Parkinson's disease. Brain 1998; 121: 451-57. [CrossRef]

32. Koller W, Pahwa R, Busenbark K, Hubble J, Wilkinson S, Lang A,et al. High frequency unilateral thalamic stimulation in the treatment of essential and parkinsonian tremor. Ann Neurol 1997; 42: 292-99. [CrossRef]

33. Dostrovsky JO, Lozano AM: Mechanisms of deep brain stimulation. MovDisord 2002; 17: 63-68. [CrossRef]

34. Fenoy AJ, Simpson RK, Jr. Risks of common complications in deep brain stimulation surgery: management and avoidance. J Neurosurg 2014; 120: 132-39. [CrossRef]

35. Sillay KA, Larson PS, Starr PA. Deep brain stimulator hardwarerelated infections: incidence and management in a large series. Neurosurgery 2008; 62: 360-66. [CrossRef]

36. Piacentino M, Pilleri M, Bartolomei L. Hardware-related infections after deep brain stimulation surgery: review of incidence, severity and management in 212 single-center procedures in the first year after implantation. Acta Neurochir 2011; 153: 2337 41. [CrossRef]

37. Benazzouz A, Gao DM, Ni ZG, Piallat B, Bouali-Benazzouz R, Benabid AL: Effect of high-frequency stimulation of the subthalamic nucleus on the neuronal activities of the substantia nigra parsreticulata and ventrolateral nucleus of the thalamus in therat. Neuroscience 2000; 99: 289-295. [CrossRef]

38. Dams J, Siebert U, Bornschein B, Volkmann J, Deuschl G, Oertel WH, et al. Cost-effectiveness of deep brain stimulation in patients with Parkinson's disease. Move Disord 2013; 28: 763-771. [CrossRef]

39. Eggington S, Valldeoriola F, Chaudhuri KR, Ashkan K, Annoni E, Deuschl G. The cost-effectiveness of deep brain stimulation in combination with best medical therapy, versus best medical therapy alone, in advanced Parkinson's disease. J Neurol 2014; 261: 106-116. [CrossRef]

40. Martinez-Ramirez D, Hu W, Bona AR, Okun MS, Wagle Shukla A. Update on deep brain stimulation in Parkinson's disease. Transl Neurodegener 2015; 4: 12. [CrossRef]

41. Benabid AL, Pollak P, Louveau A, Henry S, de Rougemont J. Combined (thalamotomy and stimulation) stereotactic surgery of the VIM thalamic nucleus for bilateral Parkinson disease. Appl Neurophysiol 1987; 50: 344-6. [CrossRef]
42. Murrow RW. Penfield's Prediction: A Mechanism for Deep Brain Stimulation. Front Neurol 2014; 5: 213. [CrossRef]

43. Agnesi F, Johnson MD, Vitek JL. Deep brain stimulation: how does it work? Handb Clin Neurol 2013; 116: 39-54. [CrossRef]

44. Baizabal-Carvallo JF, Kagnoff MN, Jimenez-Shahed J, Fekete $\mathrm{R}$, Jankovic J. The safety and efficacy of thalamic deep brain stimulation in essential tremor: 10 years and beyond. J Neurol Neurosurg Psychiatry 2014; 85: 567-72. [CrossRef]

45. Zhang K, Bhatia S, Oh MY, Cohen D, Angle C, Whiting D. Longterm results of thalamic deep brain stimulation for essential tremor. J Neurosurg 2010; 112: 1271-76. [CrossRef]

46. Pilitsis JG, Metman LV, Toleikis JR, Hughes LE, Sani SB, Bakay RA. Factors involved in long-term efficacy of deep brain stimulation of the thalamus for essential tremor. J Neurosurg 2008; 109: 640-46. [CrossRef]

47. Blomstedt P, Hariz GM, Hariz MI, Koskinen LO. Thalamic deep brain stimulation in the treatment of essential tremor: a long-term follow-up. Br J Neurosurg 2007; 21: 504-09. [CrossRef]

48. Benabid AL, Pollak P, Gao D, Hoffmann D, Limousin P, Gay $\mathrm{E}$, et al. Chronic electrical stimulation of the ventralis intermedius nucleus of the thalamus as a treatment of movement disorders. J Neurosurg 1996; 84: 203-14. [CrossRef]

49. Favilla CG, Ullman D, Wagle Shukla A, Foote KD, Jacobson CEt, Okun MS. Worsening essential tremor following deep brain stimulation: disease progression versus tolerance. Brain 2012; 135: 1455-62. [CrossRef]

50. Paul S. Larson, Deep Brain Stimulation for Movement Disorders, Neurotherapeutics 2014; 11: 465-74. [CrossRef]

51. Blomstedt P, Lindvall P, Linder J, Olivecrona M, Forsgren L, Hariz MI. Reoperation after failed deep brain stimulation for essential tremor. World Neurosurg 2012; 78: 554. [CrossRef]

52. Blomstedt P, Sandvik U, Hariz MI, Fytagoridis A, Forsgren L, Hariz GM, et al. Influence of age, gender and severity of tremor on outcome after thalamic and subthalamic DBS for essential tremor. Parkinsonism Relat Disord 2011; 17: 61720. [CrossRef]

53. Paul S. Larson, Deep Brain Stimulation for Movement Disorders, Neurotherapeutics 2014; 11: 465-74. [CrossRef]

54. Chapuis S, Ouchchane L, Metz O, Gerbaud L, Durif F. Impact of the motor complications of Parkinson's disease on the quality of life. Mov Disord 2005; 20: 224-30. [CrossRef]

55. Damiano AM, McGrath MM, Willian MK, Snyder CF, LeWitt PA, Reyes PF, et al. Evaluation of a measurement strategy for Parkinson's disease: assessing patient health-related quality of life. Qual Life Res 2000; 9: 87-100. [CrossRef]

56. Fasano A, Romito LM, Daniele A, Piano C, Zinno M, Bentivoglio AR, et al. Motor and cognitive outcome in patients with Parkinson's disease 8 years after subthalamic implants. Brain 2010; 133: 2664-76. [CrossRef]

57. Castrioto A, Lozano AM, Poon YY, Lang AE, Fallis M, Moro E. Ten-year outcome of subthalamic stimulation in Parkinson disease: a blinded evaluation. Arch Neurol 2011; 68: 1550-56. [CrossRef]

58. Alexia-Sabine Moldovan, Stefan Jun Groiss, Saskia Elben, Martin Südmeyer, Alfons Schnitzler, Lars WojteckiThe treatment of Parkinson's disease with deep brain stimulation: current issues Neural Regeneration Research 2015; 10: 1018-22. [CrossRef]

59. Weaver FM, Follett KA, Stern M, Luo P, Harris CL, et al. Randomized trial of deep brain stimulation for Parkinson disease: thirty-six-month outcomes. Neurology 2012; 79: 55-65. [CrossRef] 
60. Moro E, Lozano AM, Pollak P, Agid Y, Rehncrona S, Volkmann $\mathrm{J}$, et al. Long-term results of a multicenter study on subthalamic and pallidal stimulation in Parkinson's disease. Mov Disord 2010; 25: 578-86. [CrossRef]

61. Volkmann J, Allert N, Voges J, Weiss PH, Freund HJ, Sturm V. Safety and efficacy of pallidal or subthalamic nucleus stimulation in advanced PD. Neurology 2001; 56: 548-51. [CrossRef]

62. Follett KA, Weaver FM, Stern M, Hur K, Harris CL, Luo P, et al. Pallidal versus subthalamic deep-brain stimulation for Parkinson's disease. N Engl J Med 2010; 362: 2077-91. [CrossRef]

63. Volkmann J, Moro E, Pahwa R. Basic algorithms for the programming of deep brain stimulation in Parkinson's disease. Mov Disord 2006; 21: 284-89. [CrossRef]

64. Ondo W, Jankovic J, Schwartz K, Almaguer M, Simpson RK. Unilateral thalamic deep brain stimulation for refractory essential tremor and Parkinson's disease tremor. Neurology 1998; 51: 1063-69. [CrossRef]

65. Benabid AL, Pollak P, Gao D, Hoffmann D, Limousin P, Gay $\mathrm{E}$, et al. Chronic electrical stimulation of the ventralis intermedius nucleus of the thalamus as a treatment of movement disorders. J Neurosurg 1996; 84: 203-14. [CrossRef]

66. Stefani A, Lozano AM, Peppe A, Stanzione P, Galati S, Tropepi $\mathrm{D}$, et al. Bilateral deep brain stimulation of the pedunculopontine and subthalamic nuclei in severe Parkinson's disease. Brain 2007; 130: 1596-1607. [CrossRef]

67. FerrayeMU, Debu B, Fraix V, Krack P, Charbardes S, Seigneuret $\mathrm{E}$, et al. Subthalamic nucleus versus pedunculopontine nucleus stimulation in Parkinson disease: synergy or antagonism? J Neural Transm 2011; 118: 1469-75. [CrossRef]

68. Stamelou M, Hoeglinger GU. Atypical parkinsonism: an update. Curr Opin Neurol 2013; 26: 401-05. [CrossRef]

69. Kleiner-Fisman G, Herzog J, Fisman DN, Tamma F, Lyons KE, Pahwa R, et al. Subthalamic nucleus deep brain stimulation summary and meta-analysis of outcomes. Mov Disord 2006; 21: 290-304. [CrossRef]

70. Bronstein JM, Tagliati M, Alterman RL, Lozano AM, Volkmann J, Stefani A, et al. Deep brain stimulation for Parkinson disease: an expert consensus and review of key issues. Arch Neurol 2011; 68: 165. [CrossRef]

71. Charles PD, Van Blercom N, Krack P, Lee SL, Xie J, Besson G, et al. Predictors of effective bilateral subthalamic nucleus stimulation for PD. Neurology 2002; 59: 932-34. [CrossRef]

72. Russmann H, Ghika J, Villemure JG, Robert B, Bogousslavsky J, Burkhard PR, et al. Subthalamic nucleus deep brain stimulation in Parkinson disease patients over age 70 years. Neurology 2004; 63: 1952-54. [CrossRef]

73. Wojtecki L, Vesper J, Schnitzler A. Interleaving programming of subthalamic deep brain stimulation to reduce side effects with goodmotor outcome in a patient with Parkinson's disease. Parkinsonism Relat Disord 2011; 17: 293-94. [CrossRef]

74. Okun MS, Gallo BV, Mandybur G, Jagid J, Foote KD, Revilla FJ, et al. Subthalamic deep brain stimulation with a constantcurrent device in Parkinson's disease: an open-label randomised controlled trial. Lancet Neurol 2012; 11: 140-49. [CrossRef]
75. Witt K, Daniels C, Reiff J, Krack P, Volkmann J, Pinsker MO, et al. Neuropsychologicaland psychiatric changes after deep brain stimulation for Parkinson's disease: a randomised, multicentre study. Lancet Neurol 2008; 7: 605-14. [CrossRef]

76. Demetriades P, Rickards H, Cavanna AE. Impulse control disorders following deep brain stimulation of the subthalamic nucleus in Parkinson's disease: clinical aspects. Parkinsons Dis 2011; 658415. [CrossRef]

77. Smeding HM, Goudriaan AE, Foncke EM, Schuurman PR, Speelman JD, Schmand B. Pathological gambling after bilateral subthalamic nucleus stimulation in Parkinson disease. J Neurol Neurosurg Psychiatry 2007; 78: 517-19. [CrossRef]

78. deSouza RM, Moro E, Lang AE, Schapira AH. Timing of deep brain stimulation in Parkinson disease: a need for reappraisal? AnnNeurol 2013; 73: 565-75. [CrossRef]

79. Schuepbach WM, Rau J, Knudsen K, Volkmann J, Krack P, Timmermann L, et al. Neurostimulation for Parkinson's disease with early motor complications. N Engl J Med 2013; 368: 61022. [CrossRef]

80. Ameer L Elaimy, Benjamin J Arthurs, Wayne T Lamoreaux, John J Demakas, Alexander R Mackay, Robert K Fairbanks et al. Gamma knife radiosurgery for movement disorders: a concise review of the literature World Journal of Surgical Oncology 2010; 8: 61 [CrossRef]

81. Niranjan A, Kondziolka D, Baser S, Heyman R, Lunsford LD. Functional outcomes after gamma knife thalamotomy for essential tremor and MS-related tremor. Neurology 2000; 55: 443-446. [CrossRef]

82. Valldeoriola F, Regidor I, Minguez-Castellanos A, Lezcano E, Garcia-Ruiz P, Rojo A, et al. Efficacy and safety of pallidal stimulation in primary dystonia: results of the Spanish multicentric study. J Neurol Neurosurg Psychiatry 2010; 81: 65-69. [CrossRef]

83. Damier P, Thobois S, Witjas T, Cuny E, Derost P, Raoul S, et al. Bilateral deep brain stimulation of the globus pallidus to treat tardive dyskinesia. Arch Gen Psychiatry 2007; 64: 170-176. [CrossRef]

84. Chang EF, Schrock LE, Starr PA, Ostrem JL. Long-term benefit sustained after bilateral pallidal deep brain stimulation in patients with refractory tardive dystonia. Stereotact Funct Neurosurg 2010; 88: 304-10.[CrossRef]

85. Skogseid IM, Ramm-Pettersen J, Volkmann J, Kerty E, Dietrichs E, Roste GK. Good long-term efficacy of pallidal stimulation in cervical dystonia: a prospective, observer-blinded study. Eur J Neurol 2012; 19: 610-15. [CrossRef]

86. Fukaya C, Katayama Y, Kano T, Nagaoka T, Kobayashi K, Oshima H, et al. Thalamic deep brain stimulation for writer's cramp. JNeurosurg 2007; 107: 977-982. [CrossRef]

87. Ghika J, Villemure JG, Miklossy J, Temperli P, Pralong E, Christen-Zaech S, et al. Postanoxic generalized dystonia improved by bilateral Voa thalamic deep brain stimulation. Neurology 2002; 58: 311-13. [CrossRef] 